\title{
Relationship of Perceived Social Support with Mental Health in Older Caregivers
}

\author{
Laura Muñoz-Bermejo ${ }^{1, * \mathbb{D}}$, José Carmelo Adsuar ${ }^{2, *} \mathbb{C}$, Salvador Postigo-Mota ${ }^{3}$, \\ Inés Casado-Verdejo ${ }^{4}$, Claudia Mara de Melo-Tavares ${ }^{5}$, Miguel Ángel Garcia-Gordillo ${ }^{6}$, \\ Jorge Pérez-Gómez ${ }^{2}$ (D) and Jorge Carlos-Vivas ${ }^{2}$ (D) \\ 1 Social Impact and Innovation in Health (InHEALTH), University of Extremadura, 10003 Cáceres, Spain \\ 2 Health, Economy, Motricity and Education Research Group (HEME), Faculty of Sport Sciences, University of \\ Extremadura, 10003 Cáceres, Spain; jorgepg100@gmail.com (J.P.-G.); jorge.carlosvivas@gmail.com (J.C.-V.) \\ 3 Department of Nursing, Faculty of Medicine, University of Extremadura, 06006 Badajoz, Spain; \\ spostigo@unex.es \\ 4 Department of Nursing and Physiotherapy of Faculty of Health Sciences, University of León, 24071 León, \\ Spain; ines.casado@unileon.es \\ 5 Department of Maternal, Child and Psychiatric Nursing, University Federal Fluminense/UFF, Rio de \\ Janeiro (RJ) 24020-140, Brasil; claudiamarauff@gmail.com \\ 6 Facultad de Administración y Negocios, Universidad Autónoma de Chile, sede Talca 3467987, Chile; \\ miguelgarciagordillo@gmail.com \\ * Correspondence: lauramunoz@unex.es (L.M-B); jadssal@unex.es (J.C.A.)
}

Received: 10 April 2020; Accepted: 22 May 2020; Published: 30 May 2020

\begin{abstract}
Background: Elderly caregivers present increased physical and mental health problems. These factors can lead to a lack of autonomy and a need for social support. This study aims to analyse the relationships between perceived social support and mental health status in elderly caregivers aged 65 and older. Methods: a cross-sectional study based on data from the Spanish National Health Survey (ENSE-17) carried out on 7023 people. The study population was restricted to 431 caregivers aged $\geq 65$ years. A study of the correlation between the mental health state and the perceived social support was carried out. Both variables were related to the sex of the caregiver. Results: Perceived social support by older caregivers is significantly related to mental health $(p=0.001)$, and stress $(p<0.001)$. Also, there is a significant relationship between perceived social support and mental well-being $(p=0.001)$, self-esteem $(p=0.005)$ and stress $(p=0.001)$ in older women caregivers. Conclusions: Older caregivers have adequate mental well-being and perceive high social support. Perceived social support can contribute to improving the mental well-being of older caregivers.
\end{abstract}

Keywords: health surveys; aged; caregivers; mental health; stress; psychological; social support

\section{Introduction}

Population ageing represents one of the greatest challenges among the developments resulting from demographic change in Western societies. As the population ages, the demand for informal caregiving by family members is constantly increasing [1]. The availability of potential caregivers in western countries is currently decreasing due to several demographic and socio-structural changes, such as lower fertility, increased mobility, and higher participation of women in the labour market [2]. The family is the main provider of care for dependent older people, and the spouse is the person who frequently takes the role of the main caregiver [3]. In many cases, adult children are providing care to their elderly parents, resulting in additional stress, which puts the caregivers' mental health at risk as well [4]. 
According to the Survey of Living Conditions in Spain (ECV-2018) [5] and The English Longitudinal Study of Ageing (ELSA-2002-16) [6], the prevalence of caring for dependents are $11 \%-13 \%$ and $14 \%-17 \%$ among older men and women, respectively. The increase of men in care supposes a new trend in informal elderly care. Also, older people who are dedicated to caring are involved in performing their function at a high hourly rate. Specifically, more than two-thirds of these people spend more than $20 \mathrm{~h}$ a week on caring [7].

The caregiving role performance by older people requires a dedication to which their capacities may be diminished. The extra effort could influence the emergence of health problems in the caregivers [8].

The care of dependent people is associated with negative physical and mental health consequences for family caregivers [9-11]. The emotional and psychological consequences of caregiving are primarily represented by subjective burden [12], anxiety, depressive symptoms [13-15], higher levels of stress [16], lower levels of subjective well-being and self-efficacy [17], and low self-perceived quality of life $[18,19]$. Prevalence studies have shown that $40.2 \%$ of elderly relative caregivers present depressive symptoms [14].

To establish environments that keep caregivers in good health and preserve adequate caregiving skills, evidence is needed on the negative effects of health care. The health consequences of caregiving can be influenced by individual and contextual factors like age and sex, the duration of caregiving as well as support through family networks or community programs [20]. Several studies have supported the role of social support in protecting and maintaining physical and psychological health [21,22].

Social support in caregivers can be measured by the perceived social support and the social support received. Perceived social support refers to the availability of help when needed, the assessment of its relevance and/or quality of such assistance. Support received refers to the origin and frequency of specific help [23].

The relationships between social support and symptoms associated with the caregiver's subjective burden depend on whether social support is measured as perceived or received. There is a relationship between perceived social support and the subjective burden. In contrast, there is no relationship between the support received and the subjective burden [24]. In this context, social support perceived as adequate or positive may be related to a less stressful situation and may favour the emotional well-being of older caregivers. Thus, emotional problems arising from the subjective burden on caregivers should be addressed as an objective of intervention by increasing social support [25]. However, to the best of our knowledge, no publication has studied the relationship between social support on mental well-being in older caregivers, previously.

Therefore, this study aims to analyse the relationship between perceived social support and mental health in caregivers aged 65 and older. If a direct correlation between perceived social support and mental health status were shown, it could make visible the need to develop strategies that implement the resources to help caregivers. Thus, preventing the emergence of emotional disturbances that worsen the mental health status of older caregivers.

\section{Experimental Section}

\subsection{Study Design}

A descriptive correlation study was carried out, taking as the primary data source the results of the Spanish National Health Survey (ENS) 2017 [9]. The survey is aimed at the group of persons who reside in primary family dwellings. If the dwelling includes two or more families, the study extends to all of them, but a survey will be carried out for each family. Stratified tri-stage sampling was used. The information collection period extends over one year, from October 2016 to October 2017, to collect data that may be affected by seasonality. 


\subsection{Sample Size Calculation}

A sample size of 97 achieves $90 \%$ power to detect a difference of -0.31 between the null hypothesis correlation of 0.09 and the alternative hypothesis correlation of 0.4 using a two-sided hypothesis test with a significance level of 0.05 [26].

\subsection{Ethical Approval}

Files for public use are not considered confidential, following Regulation (EU) 2016/679 of the European Parliament and of the Council of 27 April 2016 on the protection of individuals concerning the processing of personal data and on the free movement of such data (which entered into force on 25 May 2016 and has been compulsory since 25 May 2018). Data protection principles do not need to be applied to anonymous information (i.e., information related to an identifiable natural person, nor to data of subject that is not, or is no longer, identifiable). Consequently, the Regulation does not affect the processing of information published by ENSE. Even for statistical or research purposes, its use does not require the approval of an accredited ethics committee.

\subsection{Participants}

We interviewed a total of 7023 participants aged 65 years or older. To be included in this analysis, participants need to meet the following inclusion criteria: (1) primary caregivers and (2) persons aged 65 years or older. After applying eligibility criteria, only 494 persons were considered for this study. Subsequently, persons who did not respond to survey items referring to mental health or perceived social support were excluded $(n=63)$. Therefore, the final sample was made up of 431 elderly caregivers ( 257 women and 174 men).

\subsection{Measures and Procedures}

A descriptive analysis was made of all sociodemographic factors, mental health characteristics and perceived social support.

Sociodemographic data. Information regarding age, sex and educational level of the participants was selected. Hours spent on care were also included. The variable "hours dedicated to caring" measures the total hourly burden of caring for persons per week. Possible responses were (a) less than $10 \mathrm{~h}$ per week, (b) $10 \mathrm{~h}$ or more per week but less than $20 \mathrm{~h}$, and (c) $20 \mathrm{~h}$ or more per week.

Relationship to the caregiver. The kinship to caregiver variable is a dichotomous variable, where the possible choices are relatives or other persons.

Mental health status. It was measured by the General Health Questionnaire (GHQ-12), whose overall score provides an assessment of the psychological health of a population [27]. The GHQ-12 is made up of 12 items with answers graduating from 0 to 3, in which the person is asked whether they have recently experienced a series of symptoms or a particular behaviour. According to this method, the maximum value that can be obtained on the scale is 36 points, and the minimum is zero points. The total score is obtained by a simple summation of the scores on each of the items. The score, therefore, ranges from $0-36$ points, from best to worst mental health. The optimal cut-off point is $2 / 3$ of the maximum score. Scores of 12 or higher indicate the possibility that the person is suffering from an emotional disorder [28]. The Spanish version of the GHQ-12 is valid and reliable, presenting a high internal consistency in the general population $(\alpha=0.86)$ and also in the population over 65 years of age $(\alpha=0.90)[29]$.

From the exploratory factor analysis, it is observed that much of the variability of the GHQ-12 items can be explained by bringing together the 12 items into 3 factors. The existence of three factors: successful coping, self-esteem and stress are described by different authors [30-32].

Through the factorial analysis forcing the grouping of three factors, it is observed that in Factor I, 6 items are gathered $(1,3,4,7,8$ and 12) and these are called "Successful Coping". In Factor II, there are 4 items $(6,9,10$ and 11) and these are called "Self-esteem". In Factor III, there are 3 items $(2,5$ and 
9) and these are called "Stress". Every question assesses the severity of a mental problem in the last few weeks using a 4-point Likert scale (0 to 3). Positive items were corrected from 0 (always) to 3 (never) and negative items from 3 (always) to 0 (never). Note that Item 9 presents loads on two factors, positively on Factor II and negatively on Factor III. The minimum value that can be reached in Factor 1 is 0 and the maximum is 18 . Factor II has a range of $0-12$ and Factor III of $0-9$. High scores indicate poorer health.

The external validity of the 3 factors are $0.82,0.70$ and 0.75 for Factors I, II and III $(p<0.001)$, respectively.

To calculate the value of each factor, a recoding has been done by grouping the answers to the questions of each factor.

Perceived Social Support. The Duke-UNC-11 Functional Social Support Questionnaire [33] was used to determine the perceived social support of older caregivers. This scale has 11 items on a Likert response scale from 1 ("much less than I want") to 5 ("as much as I want"). The score ranges from 11 to 55 points. In the Spanish version, a cut-off point was chosen at the 15 th percentile, corresponding to a score of $<32$. A score of 32 or more indicates standard support, while a score lower than 32 points indicates low perceived social support. The Spanish version of this questionnaire is valid and reliable [34], showing excellent internal consistency in the Spanish population $(\alpha=0.90)$.

\subsection{Statistical Analysis}

Statistical analysis was performed using the software IBM SPSSC) version 22 (IBM, Armonk, NY, USA). Descriptive statistics are presented as mean and standard deviation, and median and interquartile range (IQR) for age, Goldberg's general health status (GHQ-12) and DukeUNC-11 perceived social support. Percentages were obtained for Level of Studies, Relationships and Hours Spent Caring.

The Kolmogorov-Smirnov test was applied to check that the sample distribution data for every variable fit a normal distribution. Results showed that all variables did not fit a normal distribution. Thus, between-group differences were analysed using the Mann-Whitney U-test for continuous variables and the $\chi^{2}$ test for categorical variables. The significant level was set at a $p$-value of 0.05 for all tests. "Don't know" and "no response" responses were considered missing data.

To evaluate possible differences between subgroups for each variable, we used the non-parametric Mann-Whitney U-test for two independent samples and the chi-square test for sex comparisons.

Subgroup comparison in GHQ-12, Factors I, II and III were also conducted according to Level of Studies, Relationships and Hours Spent Caring. Besides, to assess the existence of significant differences between the levels of GHQ-12, Factors I, II and III according to Level of Studies, Relationships and Hours Spent Caring, the Kruskal-Wallis non-parametric test was used for the variables GHQ-12, Factors I, II and III, using the different levels of the variables Level of Studies, Relationships and Hours Spent Caring. For posthoc analysis, the Mann-Whitney U-test was used for pairwise comparisons, with the corresponding Bonferroni correction to counteract the problem of multiple comparisons, establishing $p<0.04$.

Spearman's Rho test was used to determine the correlation between GHQ-12 and Duke-UNC-11. Hypothesis contrasts were considered significant when $p<0.05$. Bonferroni correction was applied for multiple comparisons, establishing $p<0.01$.

\section{Results}

Table 1 shows the descriptive statistics of the total sample $(n=431)$ and by sex subgroups: women $(n=257)$ and men $(n=174)$. The average age of the sample was $73.3(6.5)$ years, with a median of 71 (10) years.

For GHQ-12, mean and median values of less than 12 points were obtained. High scores indicate the possibility that the person is suffering from an emotional disorder. The results of Duke-UNC-11 means and medians were between 47 and 50 points. Values above 32 indicate low social support. 
Table 1. Sociodemographic characteristics and dimensions-subscales of the Goldberg General Health Questionnaire GHQ-12 and Duke-UNC Functional Social Support Questionnaire in older caregivers. Spain, 2017.

\begin{tabular}{|c|c|c|c|c|}
\hline Variables & Total Sample $n=431$ & Women $n=257$ & Men $n=174$ & $p$-Value \\
\hline Age (years) & & & & $0.459^{\mathrm{a}}$ \\
\hline Median (IQR) & $71(10)$ & $71(15)$ & $71(10)$ & \\
\hline Mean (SD) & $73.3(6.5)$ & $73.2(6.3)$ & $73.6(6.9)$ & \\
\hline Range & $65-93$ & $65-92$ & $65-93$ & \\
\hline Level of Studies & & & & $<0.001^{\mathrm{b}}$ \\
\hline Cannot Read or Write & $17(3.9 \%)$ & $14(5.4 \%)$ & $3(1.7 \%)$ & \\
\hline Primary School & $233(54.1 \%)$ & $144(56 \%)$ & $89(51.1 \%)$ & \\
\hline Secondary School & $96(22.3 \%)$ & $53(20.6 \%)$ & $43(24.7 \%)$ & \\
\hline Vocational Training & $24(5.6 \%)$ & $15(5.8 \%)$ & $9(5.2 \%)$ & \\
\hline University Studies & $61(14.2 \%)$ & $31(12.1 \%)$ & $30(17.2) \%$ & \\
\hline Relationship & & & & $<0.001^{\mathrm{b}}$ \\
\hline Family Members & $401(93 \%)$ & $238(92.6 \%)$ & $163(93.7 \%)$ & \\
\hline Other People & $30(7 \%)$ & $19(7.4 \%)$ & $11(6.3 \%)$ & \\
\hline Hours Dedicated to Caring & & & & $<0.001^{b}$ \\
\hline Less than $10 \mathrm{~h}$ per week & $95(22 \%)$ & $50(19.5 \%)$ & $45(25.9 \%)$ & \\
\hline $\begin{array}{c}10 \mathrm{~h} \text { or more a week, but less } \\
\text { than } 20 \mathrm{~h}\end{array}$ & $61(14.2 \%)$ & $25(9.7 \%)$ & $36(20.7 \%)$ & \\
\hline More than $20 \mathrm{~h}$ a week & $275(63.8 \%)$ & $182(70.8 \%)$ & $93(53.4 \%)$ & \\
\hline GHQ-12 (Mental Health) & & & & $0.001^{\mathrm{a}}$ \\
\hline Median (IQR) & $11(6)$ & $11(6)$ & $9(5)$ & \\
\hline Mean (SD) & $11.3(5.1)$ & $12(5.3)$ & $10.2(4.6)$ & \\
\hline Range & $0-36$ & $4-36$ & $0-36$ & \\
\hline FI: Successful coping & & & & $0.006^{\mathrm{a}}$ \\
\hline Median (IQR) & $6(1)$ & $6(1)$ & $6(0)$ & \\
\hline Mean (SD) & $6,5(1,9)$ & $6,8(2)$ & $6,2(1.7)$ & \\
\hline Range & $0-18$ & $1-18$ & $0-18$ & \\
\hline FII: Self-esteem & & & & $0.038^{a}$ \\
\hline Median (IQR) & $1(3)$ & $2(3)$ & $1(3)$ & \\
\hline Mean (SD) & $1.7(1.7)$ & $1.8(1.9)$ & $1.5(1.6)$ & \\
\hline Range & $0-9$ & $0-9$ & $0-9$ & \\
\hline FIII: Stress & & & & $<0.001^{a}$ \\
\hline Median (IQR) & $3(3)$ & $3(4)$ & $2(2)$ & \\
\hline Mean (SD) & $3(2.5)$ & $3.3(2.3)$ & $2.5(2.1)$ & \\
\hline Range & $0-9$ & $0-9$ & $0-9$ & \\
\hline $\begin{array}{l}\text { Duke-UNC-11 (Perceived } \\
\text { Social Support) }\end{array}$ & & & & $0.314^{\mathrm{a}}$ \\
\hline Median (IQR) & $49(9)$ & $50(12)$ & $48.5(10)$ & \\
\hline Mean (SD) & $47.2(7.6)$ & $47.3(8.2)$ & $47.1(6.9)$ & \\
\hline Range & $17-55$ & $17-55$ & $20-55$ & \\
\hline $\begin{array}{l}\text { Normal Perceived Social } \\
\text { Support }\end{array}$ & $415(96.3)$ & $245(95.3)$ & $170(97.7)$ & $<0.001^{b}$ \\
\hline $\begin{array}{c}\text { Low Perceived Social } \\
\text { Support }\end{array}$ & $16(3.7)$ & $12(4.7)$ & $4(2.3)$ & $<0.001^{\mathrm{b}}$ \\
\hline
\end{tabular}

The variables Level of Studies, Relationship and Hours Spent Caring, Normal Perceived Social Support and Low Perceived Social Support are presented as the total number of participants who fulfilled that condition (percentage for the entire sample). Goldberg's general health status (GHQ-12): Points from 0 to 36 where 0 -better mental health and 36-worse mental health; FI-Successful Coping: Points from 0 to 18 where 0 -better successful coping and 18-worse successful coping; FII-Self-esteem: Points from 0 to 9 where 0 -better self-esteem and 9-worse self-esteem; FIII-Stress: Points from 0 to 9 where 0 -no stress and 9-intense stress; Duke-UNC-11: Scores between 11 and 55 , a value $\geq 32$ means normal perceived social support and a value $<32$ means low perceived social support. $p$-value: a $p$-value from $\mathrm{U}$ Mann-Whitney test and ${ }^{\mathrm{b}} p$-value from $\mathrm{x}^{2}$ test.

Statistically significant differences $(p \leq 0.05)$ were found between the sex of older caregivers and the level of studies ( $p=<0.001)$, relationship to the care recipient $(p=<0.001)$, hours spent caring $(p=<0.001)$, mental well-being $(p=0.001)$, successful coping $(p=0.006)$, self-esteem $(p=0.038)$, stress $(p=<0.001)$ and normal and low social support $(p=<0.001)$. 
Tables 2-5 show the differences between the subgroups of the level of studies, relationship with the recipient of care and hours dedicated to caring in the results of the level of GHQ-12 (Mental Health), Factor I (Successful Overcoming), Factor II (Self-esteem) and Factor III (Stress), respectively.

Table 2. Comparison of GHQ-12 according to the level of studies, relationship with the care recipient and hours spent in care.

\begin{tabular}{|c|c|c|c|c|c|c|c|c|}
\hline Variables & Le & & GHQ-12 & SG & Means Diff & Medians Diff & $p^{*}$ & $p^{* *}$ \\
\hline \multirow{20}{*}{$\begin{array}{l}\text { Level of } \\
\text { Studies }\end{array}$} & \multirow{5}{*}{1} & & & 2 & 2.6 & 2 & \multirow{20}{*}{$<0.001$} & 0.118 \\
\hline & & Median (IR) & $13(9)$ & 3 & 4.8 & 4 & & 0.005 \\
\hline & & Mean (SD) & $14.7(7.0)$ & 4 & 3.4 & 1.5 & & 0.120 \\
\hline & & & & 5 & 5.6 & 3.9 & & 0.001 \\
\hline & & & & 1 & -2.6 & -2 & & 0.118 \\
\hline & \multirow{4}{*}{2} & Median (IR) & $11(7)$ & 3 & 2.2 & 2 & & $<0.001$ \\
\hline & & Mean (SD) & $12.1(5.4)$ & 4 & 0.8 & 3.1 & & 0.489 \\
\hline & & & & 5 & 3 & 3 & & $<0.001$ \\
\hline & & & & 1 & -4.8 & -4 & & 0.005 \\
\hline & \multirow{4}{*}{3} & Median (IR) & $9(5)$ & 2 & -2.2 & -2 & & $<0.001$ \\
\hline & & Mean (SD) & $9.9(4.0)$ & 4 & -1.4 & -2.5 & & 0.221 \\
\hline & & & & 5 & 0.8 & 1 & & 0.198 \\
\hline & & & & 1 & -3.4 & -1.5 & & 0.120 \\
\hline & \multirow{3}{*}{4} & Median (IR) & $11.5(6)$ & 2 & -0.8 & 0.5 & & 0.489 \\
\hline & & Mean (SD) & $11.3(4.8)$ & 3 & 1.4 & 2.5 & & 0.221 \\
\hline & & & & 5 & 2.2 & 3.5 & & 0.048 \\
\hline & \multirow{4}{*}{5} & & & 1 & -5.6 & -5 & & 0.001 \\
\hline & & Median (IR) & $8(6)$ & 2 & -3 & -3 & & $<0.001$ \\
\hline & & Mean (SD) & $9.1(4.0)$ & 3 & -0.8 & -1 & & 0.198 \\
\hline & & & & 4 & -2.2 & -3.5 & & 0.048 \\
\hline \multirow{3}{*}{ Relationship } & & Median (IR) & $11(6)$ & 2 & 1 & -0.5 & \multirow{3}{*}{ NA } & 0.541 \\
\hline & & Mean (SD) & $11.3(5.2)$ & 2 & 1 & -0.3 & & 0.541 \\
\hline & 2 & $\begin{array}{l}\text { Median (IR) } \\
\text { Mean (SD) }\end{array}$ & $\begin{array}{c}11.5(7) \\
10.3(3.8)\end{array}$ & 1 & -1 & 0.5 & & 0.541 \\
\hline \multirow{6}{*}{$\begin{array}{l}\text { Hours } \\
\text { Dedicated } \\
\text { to Caring }\end{array}$} & \multirow{2}{*}{1} & Median (IR) & $10(6)$ & 2 & -0.6 & 0 & \multirow{6}{*}{0.011} & 0.361 \\
\hline & & Mean (SD) & $9.9(4.0)$ & 3 & -2 & -1 & & 0.004 \\
\hline & & Median (IR) & $10(4.5)$ & 1 & 0.6 & 0 & & 0.361 \\
\hline & 2 & Mean (SD) & $10.5(3.9)$ & 3 & -1.4 & -1 & & 0.144 \\
\hline & \multirow{2}{*}{3} & Median (IR) & $11(7)$ & 1 & 2 & 1 & & 0.004 \\
\hline & & Mean (SD) & $11.9(5.6)$ & 2 & 1.4 & 1 & & 0.144 \\
\hline
\end{tabular}

* Kruskal-Wallis global for $p=0.05$, using as an answer, the Mental Health according to GHQ-12, and as factors, the Level of Studies: 1 (Cannot read or write), 2 (Primary School), 3 (Secondary School), 4 (Vocational Training) or 5 (University Studies); Relationship: 1 (Family members) or 2 (Other people); Hours Dedicated to Caring: 1 (Less than $10 \mathrm{~h}$ per week), 2 (10 h or more a week, but less than $20 \mathrm{~h}$ ) or 3 (More than $20 \mathrm{~h}$ a week). ** Mann-Whitney post hoc U analysis, with Bonferroni correction factor having $p=0.004$. GHQ-12 (values 0-36). SG: subgroups of Level of Studies (values 1-5), Relationship (1-2), Hours Dedicated to Caring (values 1-3). Mean Diff: the difference between the average values of GHQ-12 for each SG level. Median Diff: the difference between the mean values of GHQ-12 for each SG level. NA: not applicable.

There is a continuous and progressive decrease in the mean values of GHQ-12, Factor I "Successful Coping", Factor II "Self-esteem" and Factor III "Stress" as the level of education increases. It is noteworthy that this continuous decrease suffers a small peak increase in those caregivers who have an intermediate level of education based on "Vocational Training". As the number of hours dedicated to caregiving increases, there is an increase in GHQ-12, Factor I, II and III values.

Besides, to evaluate the existence of significant differences between the levels of GHQ-12, Factors I, II and III, according to the level of studies, relationships and hours dedicated to caring, the Kruskal-Wallis non-parametric test was carried out using the different levels of the subgroups (SG) as factors. In all cases, $p<0.005$.

Since in all four cases, the result of the Kruskal-Wallis test indicated the existence of significant differences in at least one of the medians, post hoc analyses were performed using the Mann-Whitney U-test for the variables GHQ-12, Factors I, II and III, to detect among which specific subgroups of study level, relationships and hours spent caring occurred these significant differences. In these analyses, Bonferroni corrections were applied to counteract the problem of multiple comparisons by obtaining $p<0.004$. 
Table 3. Comparison of Factor I "Successful Coping" according to the level of studies, relationship and hours dedicated to caring.

\begin{tabular}{|c|c|c|c|c|c|c|c|c|}
\hline Variables & & & $\begin{array}{c}\text { FI } \\
\text { Successful Coping }\end{array}$ & SG & Means Diff & Medians Diff & $p^{*}$ & $p^{* *}$ \\
\hline \multirow{20}{*}{$\begin{array}{l}\text { Level of } \\
\text { Studies }\end{array}$} & \multirow{3}{*}{1} & & & 2 & 0.6 & 0 & \multirow{20}{*}{$<0.001$} & 0.777 \\
\hline & & Median (IQR) & $6(2.5)$ & 3 & 1.3 & 0 & & 0.056 \\
\hline & & Mean (SD) & $7.4(3.0)$ & 4 & 0.6 & 0 & & 0.988 \\
\hline & & & & 5 & 1.5 & 0 & & 0.091 \\
\hline & \multirow{4}{*}{2} & \multirow{4}{*}{$\begin{array}{l}\text { Median (IQR) } \\
\text { Mean (SD) }\end{array}$} & & 1 & -0.6 & 0 & & 0.777 \\
\hline & & & $6(1)$ & 3 & 0.7 & 0 & & $<0.001$ \\
\hline & & & $6.8(2.1)$ & 4 & 0.0 & 0 & & 0.723 \\
\hline & & & & 5 & 0.9 & 0 & & 0.004 \\
\hline & \multirow{4}{*}{3} & \multirow{4}{*}{$\begin{array}{l}\text { Median (RI) } \\
\text { Media (DT) }\end{array}$} & \multirow{4}{*}{$\begin{array}{c}6(0) \\
6.1(1.2)\end{array}$} & 1 & -1.3 & 0 & & 0.056 \\
\hline & & & & 2 & -0.7 & 0 & & $<0.001$ \\
\hline & & & & 4 & -0.7 & 0 & & 0.009 \\
\hline & & & & 5 & 0.2 & 0 & & 0.687 \\
\hline & \multirow{4}{*}{4} & \multirow{4}{*}{$\begin{array}{l}\text { Median (RI) } \\
\text { Media (DT) }\end{array}$} & \multirow{4}{*}{$\begin{array}{c}6(1.8) \\
6.8(1.6)\end{array}$} & 1 & -0.6 & 0 & & 0.988 \\
\hline & & & & 2 & 0.0 & 0 & & 0.723 \\
\hline & & & & 3 & 0.7 & 0 & & 0.009 \\
\hline & & & & 5 & 0.9 & 0 & & 0.023 \\
\hline & \multirow{4}{*}{5} & \multirow{4}{*}{$\begin{array}{l}\text { Median (IQR) } \\
\text { Mean (SD) }\end{array}$} & \multirow{4}{*}{$\begin{array}{c}6(0) \\
5.9(1.5)\end{array}$} & 1 & -1.5 & 0 & & 0.091 \\
\hline & & & & 2 & -0.9 & 0 & & 0.004 \\
\hline & & & & 3 & -0.2 & 0 & & 0.687 \\
\hline & & & & 4 & -0.9 & 0 & & 0.023 \\
\hline \multirow{4}{*}{ Relationship } & 1 & Median (IQR) & 6(1) & 2 & 0.5 & 0 & \multirow{4}{*}{ NA } & 0.164 \\
\hline & 1 & Mean (SD) & $6.6(1.9)$ & 2 & 0.5 & & & 0.104 \\
\hline & 2 & Median (RI) & $6(0)$ & 1 & -0.5 & 0 & & 0.164 \\
\hline & 2 & Media (DT) & $6.1(1.1)$ & 1 & & & & \\
\hline \multirow{6}{*}{$\begin{array}{l}\text { Hours } \\
\text { Dedicated to } \\
\text { Caring }\end{array}$} & \multirow{2}{*}{1} & Median (RI) & $6(0)$ & 2 & -0.2 & 0 & \multirow{6}{*}{0.028} & 0.222 \\
\hline & & Median (DT) & $6.1(1.3)$ & 3 & -0.7 & 0 & & 0.010 \\
\hline & 2 & Median (IQR) & $6(0)$ & 1 & 0.2 & 0 & & 0.222 \\
\hline & \multirow{3}{*}{3} & Mean (SD) & $6.3(1.2)$ & 3 & $-0,5$ & 0 & & 0.329 \\
\hline & & Median (IQR) & $6(1)$ & 1 & 0.7 & 0 & & 0.010 \\
\hline & & Mean (SD) & $6.8(2.1)$ & 2 & 0.5 & 0 & & 0.329 \\
\hline
\end{tabular}

* Kruskal-Wallis global for $p=0.05$, using as an answer, the Mental Health according to Factor I "Successful Coping", and as factors, the Level of Studies: 1 (Cannot read or write), 2 (Primary School), 3 (Secondary School), 4 (Vocational Training) or 5 (University Studies); Relationship: 1 (Family members) or 2 (Other people); Hours Dedicated to Caring: 1 (Less than $10 \mathrm{~h}$ per week), 2 (10 h or more a week, but less than $20 \mathrm{~h}$ ) or 3 (More than $20 \mathrm{~h}$ a week). ** Mann-Whitney post hoc U analysis with Bonferroni correction factor having $p=0.004$. Factor I "Successful Coping" (values 0-18). SG: subgroups of Level of Studies (values 1-5), Relationship (1-2), Hours Dedicated to Caring (values 1-3). Mean Diff: the difference between the average values of Factor I "Successful Coping" for each SG level. Median Diff: the difference between the mean values of Factor I "Successful Coping" for each SG level. NA: not applicable.

The results of these post hoc analyses show that the significant differences in GHQ-12 are mainly among the lower education subgroups compared to those with university education and among the subgroups that spend less than $10 \mathrm{~h}$ per week in caregiving and those that spend more than $20 \mathrm{~h}$ per week. In the results for Factors I and III, significant differences are shown between elderly caregivers with intermediate education and those with higher education. In Factor II, there are significant differences between those with lower and higher studies. Also, significant differences are shown between those who spend less than $10 \mathrm{~h}$ per week on caregiving compared to those who spend more than $20 \mathrm{~h}$ a week on caregiving.

The Spearman correlation coefficient was calculated for GHQ-12, Factors I, II and III, according to the Duke-UNC-11 by the older caregivers in the sample. Besides, the calculation was made both generally for the sample as a whole and independently for the sex subgroup within the perceived social support (Table 6). A significant correlation was obtained for both the variable GHQ-12 $(R=-0.153)$ and FIII ( $\mathrm{R}=-0.199)$ as far as Duke-UNC-11-Perceived Social Support was concerned for the analysis of the total sample. Both values showed a direct negative correlation. Similarly, in the calculation of the respective correlation coefficients of the women in the sample, significant correlations were obtained with a value of $R=-0.236$ for the association between GHQ-12 and Duke-UNC-11, the value of $R=-0.174$ for the relationship between FII and Duke-UNC-11, and the value of $R=-0.303$ for the relationship between FIII and Duke-UNC-11. 
Table 4. Comparison of Factor II "Self-esteem" according to the level of studies, relationship and hours dedicated to caring.

\begin{tabular}{|c|c|c|c|c|c|c|c|c|}
\hline Variables & & & $\begin{array}{c}\text { FII } \\
\text { Self-esteem }\end{array}$ & SG & Means Diff & Medians Diff & $p^{*}$ & $p^{* *}$ \\
\hline \multirow{20}{*}{ Level of Studies } & \multirow{4}{*}{1} & & & 2 & 1.1 & 1 & \multirow{20}{*}{$<0.001$} & 0.045 \\
\hline & & Median (IQR) & $3(3)$ & 3 & 1.8 & 2 & & 0.001 \\
\hline & & Mean (SD) & $3.1(2.3)$ & 4 & 1.6 & 2 & & 0.018 \\
\hline & & & & 5 & 2 & 3 & & $<0.001$ \\
\hline & \multirow{4}{*}{2} & \multirow{5}{*}{$\begin{array}{l}\text { Median (IQR) } \\
\text { Mean (SD) }\end{array}$} & & 1 & -1.1 & -1 & & 0.045 \\
\hline & & & $2(3)$ & 3 & 0.7 & 1 & & 0.001 \\
\hline & & & $2.0(1.8)$ & 4 & 0.5 & 1 & & 0.176 \\
\hline & & & & 5 & 0.9 & 2 & & $<0.001$ \\
\hline & \multirow{5}{*}{3} & & \multirow{4}{*}{$\begin{array}{c}1(3) \\
1.3(1.5)\end{array}$} & 1 & -1.8 & -2 & & 0.001 \\
\hline & & \multirow{3}{*}{$\begin{array}{l}\text { Median (RI) } \\
\text { Median (DT) }\end{array}$} & & 2 & -0.7 & -1 & & 0.001 \\
\hline & & & & 4 & -0.2 & 0 & & 0.588 \\
\hline & & & & 5 & 0.2 & 1 & & 0.399 \\
\hline & & \multirow{4}{*}{$\begin{array}{l}\text { Median (RI) } \\
\text { Median (DT) }\end{array}$} & \multirow{4}{*}{$\begin{array}{c}1(3) \\
1.5(1.7)\end{array}$} & 1 & -1.6 & -2 & & 0.018 \\
\hline & \multirow{3}{*}{4} & & & 2 & -0.5 & -1 & & 0.176 \\
\hline & & & & 3 & 0.4 & 0 & & 0.588 \\
\hline & & & & 5 & 0.4 & 1 & & 0.283 \\
\hline & \multirow{4}{*}{5} & \multirow{4}{*}{$\begin{array}{l}\text { Median (IQR) } \\
\text { Mean (SD) }\end{array}$} & & 1 & -2 & -3 & & $<0.001$ \\
\hline & & & $0(2)$ & 2 & -0.9 & -2 & & $<0.001$ \\
\hline & & & $1.1(1.3)$ & 3 & -0.2 & -1 & & 0.399 \\
\hline & & & & 4 & -0.4 & -1 & & 0.283 \\
\hline \multirow{4}{*}{ Relationship } & \multirow{2}{*}{1} & Median (IQR) & $1(3)$ & \multirow{2}{*}{2} & \multirow{2}{*}{1.1} & \multirow{2}{*}{0} & \multirow{4}{*}{ NA } & \multirow{2}{*}{0.684} \\
\hline & & Mean (SD) & $2.6(1.8)$ & & & & & \\
\hline & \multirow{2}{*}{2} & Median (IQR) & $1(3)$ & 1 & -1.1 & 0 & & 0.684 \\
\hline & & Mean (SD) & $1.5(1.4)$ & & & $\sigma$ & & 0.007 \\
\hline \multirow{6}{*}{$\begin{array}{l}\text { Hours Dedicated } \\
\text { to Caring }\end{array}$} & \multirow{2}{*}{1} & Median (IQR) & $1(2)$ & 2 & -0.2 & 0 & \multirow{6}{*}{0.009} & 0.455 \\
\hline & & Mean (SD) & $1.3(1.3)$ & 3 & -0.6 & -1 & & 0.003 \\
\hline & \multirow{2}{*}{2} & Median (IQR) & $1(3)$ & 1 & 0.2 & 0 & & 0.455 \\
\hline & & Mean (SD) & $1.5(1.5)$ & 3 & -0.4 & -1 & & 0.123 \\
\hline & \multirow{2}{*}{3} & Median (IQR) & $2(3)$ & 1 & 0.6 & 1 & & 0.003 \\
\hline & & Mean (SD) & $1.9(1.9)$ & 2 & 0.4 & 1 & & 0.123 \\
\hline
\end{tabular}

* Kruskal-Wallis global for $p=0.05$, using as an answer, the Mental Health according to Factor II "Self-esteem", and as factors, the Level of Studies: 1 (Cannot read or write), 2 (Primary School), 3 (Secondary School), 4 (Vocational Training) or 5 (University Studies); Relationship: 1 (Family members) or 2 (Other people); Hours Dedicated to Caring: 1 (Less than $10 \mathrm{~h}$ per week), 2 (10 h or more a week, but less than $20 \mathrm{~h}$ ) or 3 (More than $20 \mathrm{~h}$ a week). ** Mann-Whitney post hoc U analysis with Bonferroni correction factor having $p=0.004$. Factor II "Self-esteem" (values 0-12). SG: subgroups of Level of Studies (values 1-5), Relationship (1-2), Hours Dedicated to Caring (values 1-3). Mean Diff: the difference between the average values of Factor I "Self-esteem" for each SG level. Median Diff: the difference between the mean values of Factor I "Self-esteem" for each SG level. NA: not applicable.

Table 5. Comparison of Factor III "Stress" according to the level of studies, relationship and hours dedicated to caring.

\begin{tabular}{|c|c|c|c|c|c|c|c|c|}
\hline Variables & & & FIII Stress & SG & Means Diff & Medians Diff & $p^{*}$ & $p^{* *}$ \\
\hline \multirow{20}{*}{ Level of Studies } & \multirow{5}{*}{1} & \multirow{5}{*}{$\begin{array}{c}\text { Median (IQR) } \\
\text { Mean (SD) }\end{array}$} & & 2 & 1 & 1 & \multirow{20}{*}{$<0.001$} & 0.122 \\
\hline & & & $4(4)$ & 3 & 1.7 & 2 & & 0.014 \\
\hline & & & $4.3(2.8)$ & 4 & 1.3 & 2 & & 0.098 \\
\hline & & & & 5 & 2.3 & 3 & & 0.003 \\
\hline & & & & 1 & -1 & -1 & & 0.122 \\
\hline & \multirow{4}{*}{2} & Median (IQR) & $3(3)$ & 3 & 0.7 & 1 & & 0.003 \\
\hline & & \multirow[t]{3}{*}{ Mean (SD) } & $3.3(2.2)$ & 4 & 0.3 & 0 & & 0.350 \\
\hline & & & & 5 & 1.3 & 2 & & $<0.001$ \\
\hline & & & & 1 & -1.7 & -2 & & 0.014 \\
\hline & \multirow{4}{*}{3} & Median (RI) & $2(3)$ & 2 & -0.7 & -1 & & 0.003 \\
\hline & & \multirow[t]{3}{*}{ Median (DT) } & $2.6(2.1)$ & 4 & -0.4 & -1 & & 0.485 \\
\hline & & & & 5 & 0.6 & 1 & & 0.084 \\
\hline & & & & 1 & -1.3 & -1 & & 0.098 \\
\hline & \multirow{3}{*}{4} & Median (RI) & $3(4)$ & 2 & -0.3 & 0 & & 0.350 \\
\hline & & \multirow[t]{3}{*}{ Median (DT) } & $3.0(2.3)$ & 3 & 0.4 & 1 & & 0.485 \\
\hline & & & & 5 & 1 & 2 & & 0.080 \\
\hline & \multirow{4}{*}{5} & & & 1 & -2.3 & -3 & & 0.003 \\
\hline & & \multirow{3}{*}{$\begin{array}{c}\text { Median (IQR) } \\
\text { Mean (SD) }\end{array}$} & $1(3)$ & 2 & -1.3 & -2 & & $<0.001$ \\
\hline & & & $2.0(2.0)$ & 3 & -0.6 & -1 & & 0.084 \\
\hline & & & & 4 & -1 & -2 & & 0.080 \\
\hline
\end{tabular}


Table 5. Cont.

\begin{tabular}{|c|c|c|c|c|c|c|c|c|}
\hline Variables & & & FIII Stress & SG & Means Diff & Medians Diff & $p^{*}$ & $p^{* *}$ \\
\hline \multirow[t]{2}{*}{ Relationship } & 1 & $\begin{array}{c}\text { Median (IQR) } \\
\text { Mean (SD) }\end{array}$ & $\begin{array}{c}3(3) \\
3.0(2.3)\end{array}$ & 2 & 0.4 & 0 & \multirow[t]{2}{*}{ NA } & 0.488 \\
\hline & 2 & $\begin{array}{c}\text { Median (IQR) } \\
\text { Mean (SD) }\end{array}$ & $\begin{array}{c}3(4.3) \\
2.6(2.1)\end{array}$ & 1 & -0.4 & 0 & & 0.488 \\
\hline \multirow{6}{*}{$\begin{array}{l}\text { Hours Dedicated } \\
\text { to Caring }\end{array}$} & & Median (IQR) & $3(3)$ & 2 & -0.1 & 0 & \multirow{6}{*}{0.082} & 0.634 \\
\hline & 1 & Mean (SD) & $2.6(2.2)$ & 3 & -0.6 & 0 & & 0.036 \\
\hline & 2 & Median (IQR) & $3(3)$ & 1 & 0.1 & 0 & & 0.634 \\
\hline & 2 & Mean (SD) & 2.7 (1.9) & 3 & -0.5 & 0 & & 0.224 \\
\hline & \multirow{2}{*}{3} & Median (IQR) & $3(4)$ & 1 & 0.6 & 0 & & 0.036 \\
\hline & & Mean (SD) & $3.2(2.3)$ & 2 & 0.5 & 0 & & 0.224 \\
\hline
\end{tabular}

* Kruskal-Wallis global for $p=0.05$, using as an answer, the Mental Health according to Factor III "Stress", and as factors, the Level of Studies: 1 (Cannot read or write), 2 (Primary School), 3 (Secondary School), 4 (Vocational Training) or 5 (University Studies); Relationship: 1 (Family members) or 2 (Other people); Hours dedicated to caring: 1 (Less than $10 \mathrm{~h}$ per week), $2(10 \mathrm{~h}$ or more a week, but less than $20 \mathrm{~h}$ ) or 3 (More than $20 \mathrm{~h}$ a week). ** Mann-Whitney post hoc U analysis with Bonferroni correction factor having $p=0.004$. Factor II "Stress" (values 0-9). SG: subgroups of Level of Studies (values 1-5), Relationship (1-2), Hours Dedicated to Caring (values 1-3). Mean Diff: the difference between the average values of Factor I "Stress" for each SG level. Median Diff: the difference between the mean values of Factor I "Stress" for each SG level. NA: not applicable.

Table 6. Relationship between the dimensions and subscales of the Goldberg General Health Questionnaire GHQ-12 and the Duke-UNC-11 Functional Social Support Questionnaire in older caregivers. Spain, 2017.

\begin{tabular}{ccccccc}
\hline & \multicolumn{3}{c}{ Duke UNC-11 (Perceived Social Support) } & & \\
\hline & \multicolumn{2}{c}{ Total Sample } & \multicolumn{2}{c}{ Women } & & Men \\
\cline { 2 - 7 } Variables & Rho & $p$ & Rho & $p$ & Rho & $p$ \\
\hline GHQ-12 (Mental Health) & -0.153 & 0.001 & -0.236 & $<0.001$ & -0.060 & 0.434 \\
FI: Coping Capacity & -0.112 & 0.020 & -0.148 & 0.017 & -0.084 & 0.272 \\
FII: Self-esteem & -0.121 & 0.012 & -0.174 & 0.005 & -0.059 & 0.440 \\
FIII: Stress & -0.199 & $<0.001$ & -0.303 & $<0.001$ & -0.067 & 0.381 \\
\hline
\end{tabular}

Rho: Spearman correlation coefficient with the Bonferroni correction factor having $p=0.01$.

\section{Discussion}

The main finding of our study is that perceived social support by older caregivers is related to mental health and stress levels. This relationship is significantly present in women, where it is also related to self-esteem.

These results are in line with previous studies $[35,36]$ that highlights the importance of social support as a variable that moderates the negative impact on the caregiver's health. Our results also show that women caregivers care for them report longer working hours, higher stress levels, and a greater decline in self-esteem and coping skills than men. Previous studies have also argued that women caregivers report a greater burden, as well as more stress and depression than men [37-39].

In this sense, the mental health of women caregivers is more impaired than that of male caregivers [40]. It may be due to their greater involvement in care in terms of both quantity and quality of care (type and manner of care). The greater involvement of women caregivers would, therefore, explain because the negative impact of caregiving is more intense for women than for men [41].

On the other hand, our results highlight that older caregivers perceive high social support and present a good state of mental health, low-stress levels and adequate levels of self-esteem and coping skills. As other research points out, informal social support provided by the family is beneficial in alleviating the burden on the caregiver and improving coping capacities [42,43]. Ongoing social support contributes to stable self-esteem [44], and the lack of social support in stressful situations has an impact on the emotional stability of the person who is seeking help [45].

As the age of caregivers increases, so does the risk of illness and autonomy limitations. In this sense, the personal effort of the caregivers is increased, and help may be needed $[8,46]$.

Our results show no significant differences in the relationship between the caregiver and the care recipient. However, other studies indicate that bivariate analyses revealed that caring for primary 
relatives (i.e., spouse, parents, and children) was associated with greater self-reported stress than caring for other family members or non-family members (such as friends, neighbours, or co-workers) [47].

Another of the study findings is that older caregivers have a decrease in GHQ-12 (increased mental well-being) as their level of education increases and as their hours of caregiving decrease. The same is true for Factors I, II and III. In line with these results, other studies show there is evidence that both men and women are at high risk of deteriorating mental health when they perform a high number of hours of care for adult dependents [48]. The caregiver's social supports can improve reduced mental health symptoms [49].

According to Survey of Health, Ageing and Retirement (SHARE, waves 1-8) and the English Longitudinal Study of Ageing (ELSA, wave 2-9), caring for a dependent person has negative effects on the caregiver's health $[4,6]$. In such care situations, the social networks in the caregivers and recipients of care that are brought in can play an important role in addressing the challenges of the care situation [50]. Increased social contacts are associated with improved health and could, therefore, be essential in protecting older caregivers [51].

The main strengths of this study are the sample size and the fact that a nationally representative survey was used. The use of the National Health Survey provides representative data on the health of the elderly care population and the relationship between sociodemographic characteristics, perceived social support and mental health. These results make it possible to identify elderly caregivers as one of the most vulnerable groups in the population. However, like all studies, it also has some limitations: (1) GHQ-12 is a screening tool, more sensitive than specific, which can lead to an overestimation of mental health problems. It should be noted that false positives are more frequent in the population aged 65 years or older (population included in this study). (2) A control group of non-caregivers aged 65 and older was not included in the study, and (3) due to this being a cross-sectional and not an intervention study, it is not possible to establish cause-effect relationships.

\section{Implications of the Study}

These findings lead to the need to include in care protocols for older people a specific assessment of perceived social supports and to establish strategies to meet their needs as caregivers. Actions of prevention, identification and attention to mental health problems should be considered as they could have an impact on the health of the caregiving population. Finally, the importance of strengthening and defending social welfare policies aimed at the comprehensive care of the elderly is highlighted, in which special attention and assessment of elderly caregivers, who due to circumstances are increasingly numerous in our society, must be included as a priority.

\section{Conclusions}

1. Older caregivers included in this study have high social support and good mental health. Self-esteem levels and coping skills are adequate, and the level of stress is low.

2. The results of this study suggest that there is a direct association between the level of studies of older caregivers and mental well-being. A higher level of studies in older caregivers is associated with greater mental well-being.

3. There can be a decline in the mental health of older caregivers if they spend more than $20 \mathrm{~h} \mathrm{a}$ week caring.

4. The mental health of older caregivers could be related to perceived social support, especially in women.

Author Contributions: Conceptualization, L.M.-B. and J.C.A.; methodology, J.C.A. and S.P.-M.; software, J.P.-G. and J.C.-V.; validation, L.M-B., I.C.-V., C.M.d.M.-T., and J.P.-G.; formal analysis, J.C.S. and M.Á.G.-G; investigation, L.M.-B. and J.P.-G; resources, S.P.-M and J.C.A.; data curation, I.C.-V. and C.M.d.M.-T.; writing-original draft preparation, L.M.-B., J.C.A., and J.C.-V.; writing-review and editing, M.Á.G.-G. and I.C.-V.; visualization and supervision, L.M.-B., J.C.A., and J.C.-V. All authors have read and agreed to the published version of the manuscript. 
Funding: This work was supported by the 4IE+ project (0499_4IE_PLUS_4_E) and funded by the Interreg V-A España-Portugal (POCTEP) 2014-2020 program.

Conflicts of Interest: The authors declare no conflict of interest.

\section{References}

1. Fujisawa, R.; Colombo, F. The Long-Term Care Workforce: Overview and Strategies to Adapt Supply to a Growing Demand; OECD Publishing: París, France, 2009.

2. Colombo, F.; Llena-Nozal, A.; Mercier, J.; Tjadens, F. Sizing up the challenge ahead. Future demographic trends and long-term care costs. In Help Wanted? Providing and Paying for Long-Term Care; Colombo, F., Llena-Nozal, A., Mercier, J., Tjadens, F., Eds.; OECD Publishing: París, France, 2011; pp. 61-84.

3. Blyth, F.M.; Cumming, R.G.; Bmabic, A.J.M.; Cousins, M.J. Caregiving in the presence of chronic pain. J. Gerontol. Ser. a-Biol. Sci. Med Sci. 2008, 63, 399-407. [CrossRef] [PubMed]

4. Börsch-Supan, A.; Andersen-Ranberg, K.; Bristle, J.; Brugiavini, A.; Jusot, F.; Litwin, H.; Weber, G. Health and Socio-Economic Status over the Life Course First Results from SHARE Waves 6 and 7; Gruyter, D., Ed.; Walter de Gruyter GmbH: Berlín, Germany, 2019.

5. INE. Encuesta de Condiciones de Vida (ECV); Instituto Nacional de Estadística: Madrid, Spain, 2018.

6. Abell, J.; Amin-Smith, N.; Banks, J.; Batty, D.; Breeden, J.; Buffe, T.; Cadar, D.; Crawford, R.; Demakakos, P.; Oliveira, C.; et al. The Dynamics of Ageing Evidence from The English Longitudinal Study of Ageing (ELSA); The Institute for Fiscal Studies: London, UK, 2018.

7. Pérez Díaz, J.; Abellán García, A.; Aceituno Nieto, P.; Ramiro Fariñas, D. Un Perfil de Las Personas Mayores en ESPAÑA, 2020; Indicadores Estadísticos Básicos; Informes Envejecimiento en red: Madrid, Spain, 2020.

8. Baster Moro, J.C. Older adults as caregivers for aged persons. Revista Cubana de Salud Pública 2012, 38, 168-173. [CrossRef]

9. Ministerio de Sanidad, Consumo y Bienestar Social. Encuesta Nacional de Salud; Ayuntamiento de Madrid: Madrid, Spain, 2017.

10. Lacey, R.E.; McMunn, A.; Webb, E. Informal caregiving patterns and trajectories of psychological distress in the UK Household Longitudinal Study. Psychol. Med. 2019, 49, 1652-1660. [CrossRef] [PubMed]

11. Sargent-Cox, K.A.; Rippon, M.; Burns, R.A. Measuring anxiety about aging across the adult lifespan. Int. Psychogeriatr. 2014, 26, 135-145. [CrossRef]

12. Guedes, A.C.; Pereira, M.d.G. Burden, Coping, Physical Symptoms and Psychological Morbidity in Caregivers of Functionally Dependent Family Members. Revista Latino-Americana De Enfermagem 2013, 21, 935-940. [CrossRef]

13. Van der Lee, J.; Bakker, T.J.; Duivenvoorden, H.J.; Droes, R.M. Multivariate models of subjective caregiver burden in dementia: A systematic review. Ageing Res. Rev. 2014, 15, 76-93. [CrossRef]

14. Loh, A.Z.; Tan, J.S.; Zhang, M.W.; Ho, R.C. The Global Prevalence of Anxiety and Depressive Symptoms among Caregivers of Stroke Survivors. J. Am. Med. Dir. Assoc. 2017, 18, 111-116. [CrossRef] [PubMed]

15. Sallim, A.B.; Sayampanathan, A.A.; Cuttilan, A.; Ho, R. Prevalence of Mental Health Disorders Among Caregivers of Patients With Alzheimer Disease. J. Am. Med. Dir. Assoc. 2015, 16, 1034-1041. [CrossRef]

16. Baboolal, N.; Davis, G.; Stewart, R.; Ramesar, J.; McRae, A. Comparisons between different elements of reported burden and common mental disorder in caregivers of ethnically diverse people with dementia in Trinidad. PLoS ONE 2018, 13, e0201165. [CrossRef]

17. Hirst, M. Carer distress: A prospective, population-based study. Soc. Sci. Med. 2005, 61, 697-708. [CrossRef]

18. Chen, M.C.; Chen, K.M.; Chu, T.P. Caregiver burden, health status, and learned resourcefulness of older caregivers. West J. Nurs. Res. 2015, 37, 767-780. [CrossRef] [PubMed]

19. Fagerstrom, C.; Elmstahl, S.; Wranker, L.S. Analyzing the situation of older family caregivers with a focus on health-related quality of life and pain: A cross-sectional cohort study. Health Qual. Life Outcomes 2020, 18, 79. [CrossRef] [PubMed]

20. Kaschowitz, J.; Brandt, M. Health effects of informal caregiving across Europe: A longitudinal approach. Soc. Sci. Med. 2017, 173, 72-80. [CrossRef] [PubMed]

21. Han, J.W.; Jeong, H.; Park, J.; Kim, T.; Kang, S.; Kim, K.; Lee, D.; Ryu, S.; Kim, S.; Yoon, J.; et al. Differential impacts of social supports on the caregiver burden in dementia. Int. Psychogeriatr. 2013, 25, S44. 
22. Rodakowski, J.; Skidmore, E.R.; Rogers, J.C.; Schulz, R. Role of social support in predicting caregiver burden. Arch. Phys. Med. Rehabil. 2012, 93, 2229-2236. [CrossRef]

23. Gottlieb, B.H.; Bergen, A.E. Social support concepts and measures. J. Psychosom. Res. 2010, 69, 511-520. [CrossRef]

24. Del-Pino-Casado, R.; Frias-Osuna, A.; Palomino-Moral, P.A.; Ruzafa-Martinez, M.; Ramos-Morcillo, A.J. Social support and subjective burden in caregivers of adults and older adults: A meta-analysis. PLoS ONE 2018, 13, e0189874. [CrossRef]

25. Chai, Y.C.; Mahadevan, R.; Ng, C.G.; Chan, L.F.; Md Dai, F. Caregiver depression: The contributing role of depression in patients, stigma, social support and religiosity. Int. J. Soc. Psychiatry 2018, 64, 578-588. [CrossRef]

26. Schober, P.; Boer, C.; Schwarte, L.A. Correlation Coefficients: Appropriate Use and Interpretation. Anesth. Analg. 2018, 126, 1763-1768. [CrossRef]

27. Goldberg, D.; Williams, P. A User's Guide to the General Health Questionnaire; NFER-Nelson, U., Ed.; Windsor: London, UK, 1988.

28. Reig-Ferrer, A.; Cabrero-Garcia, J.; Lizan Tudela, L. Assessment of functional capacity, psychological well-being and mental health in primary care. Aten. Primaria. 2009, 41, 515-519. [CrossRef]

29. Rocha, K.B.; Perez, K.; Rodriguez-Sanz, M.; Borrell, C.; Obiols, J.E. Psychometric properties and normative values of General Health Questionnaire (GHQ-12) in Spanish population. Int. J. Clin. Health Psychol. 2011, 11, 125-139.

30. Graetz, B. Multidimensional properties of the General Health Questionnaire. Soc. Psychiatry Psychiatr. Epidemiol. 1991, 26, 132-138. [CrossRef] [PubMed]

31. Campbell, A.; Knowles, S. A confirmatory factor analysis of the GHQ12 using a large Australian sample. Eur. J. Psychol. Assess. 2007, 23, 2-8. [CrossRef]

32. Sanchez-Lopez, M.d.P.; Dresch, V. The 12-Item General Health Questionnaire (GHQ-12): Reliability, external validity and factor structure in the Spanish population. Psicothema 2008, 20, 839-843.

33. Broadhead, W.E.; Gehlbach, S.H.; Degruy, F.V.; Kaplan, B.H. The Duke-Unc Functional Social Support Questionnaire-Measurement of Social Support in Family Medicine Patients. Med Care 1988, 26, 709-723. [CrossRef]

34. Bellon Saameno, J.A.; Delgado Sanchez, A.; Luna del Castillo, J.D.; Lardelli Claret, P. Validity and reliability of the Duke-UNC-11 questionnaire of functional social support. Aten. Primaria 1996, 18, 153-156.

35. Kate, N.; Grover, S.; Kulhara, P.; Nehra, R. Relationship of caregiver burden with coping strategies, social support, psychological morbidity, and quality of life in the caregivers of schizophrenia. Asian J. Psychiatry 2013, 6, 380-388. [CrossRef]

36. Melrose, K.L.; Brown, G.D.; Wood, A.M. When is received social support related to perceived support and well-being? When it is needed. Pers. Individ. Dif. 2015, 77, 97-105. [CrossRef]

37. Kim, H.; Chang, M.; Rose, K.; Kim, S. Predictors of caregiver burden in caregivers of individuals with dementia. J. Adv. Nurs. 2012, 68, 846-855. [CrossRef]

38. Li, Q.P.; Mak, Y.W.; Loke, A.Y. Spouses' experience of caregiving for cancer patients: A literature review. Int. Nurs. Rev. 2013, 60, 178-187. [CrossRef]

39. Litwin, H.; Stoeckel, K.J.; Roll, A. Relationship status and depressive symptoms among older co-resident caregivers. Aging Ment. Health 2014, 18, 225-231. [CrossRef] [PubMed]

40. Metcalfe, I.M.; Padilla, I.L.; Del Rio Lozano, M.; Gomez, C.C.; Sobrado, M.M.; Calvente, M.D.M.G. Gender inequalities in the impacts of informal elderly caregiving in Gipuzkoa: CUIDAR-SE study. Revista espanola de salud publica 2019, 93, e201901002.

41. Larranaga, I.; Martin, U.; Bacigalupe, A.; Maria Begiristain, J.; Jose Valderrama, M.; Arregi, B. Impact of informal caregiving on caregivers' health and quality of life: Analysis of gender inequalities. Gaceta Sanitaria 2008, 22, 443-450. [CrossRef] [PubMed]

42. Guo, M.; Li, S.; Liu, J.; Sun, F. Family Relations, Social Connections, and Mental Health among Latino and Asian Older Adults. Res. Aging 2015, 37, 123-147. [CrossRef]

43. Shiba, K.; Kondo, N.; Kondo, K. Informal and Formal Social Support and Caregiver Burden: The AGES Caregiver Survey. J. Epidemiol. 2016, 26, 622-628. [CrossRef] 
44. Whitley, D.M.; Kelley, S.J.; Lamis, D.A. Depression, Social Support, and Mental Health: A Longitudinal Mediation Analysis in African American Custodial Grandmothers. Int. J. Aging Human Dev. 2016, 82, 166-187. [CrossRef]

45. Kobayasi, D.Y.; Rodrigues, R.A.P.; Fhon, J.R.S.; Silva, L.M.; Souza, A.C.d.; Chayamiti, E.M.P.C. Sobrecarga, rede de apoio social e estresse emocional do cuidador do idoso. Avances en Enfermería 2019, 37, 140-148. [CrossRef]

46. Marcos, M.M.; De la Cuesta Benjumea, C. The experience of women care cargivers with chronic conditions of dependent relatives. Aten. Primaria 2016, 48, 77-84. [CrossRef]

47. Penning, M.J.; Wu, Z. Caregiver Stress and Mental Health: Impact of Caregiving Relationship and Gender. Gerontologist 2016, 56, 1102-1113. [CrossRef]

48. Masanet, E.; La Parra, D. Relationship between the Number of Hours of Informal Care and the Mental Health Status of Caregivers. Revista Espanola De Salud Publica 2011, 85, 257-266. [CrossRef]

49. Tyler, C.M.; Henry, R.S.; Perrin, P.B.; Watson, J.; Villasenor, T.; Lageman, S.K.; Smith, E.R.; Curiel, G.R.; Avila, J.; Maldonado, M.E.J.; et al. Structural Equation Modeling of Parkinson's Caregiver Social Support, Resilience, and Mental Health: A Strength-Based Perspective. Neurol. Res. Int. 2020, 2020, 7906547. [CrossRef] [PubMed]

50. Litwin, H.; Stoeckel, K.J.; Schwartz, E. Social networks and mental health among older Europeans: Are there age effects? Eur. J. Ageing 2015, 12, 299-309. [CrossRef] [PubMed]

51. Cornwell, B.; Laumann, E.O. The health benefits of network growth: New evidence from a national survey of older adults. Soc. Sci. Med. 2015, 125, 94-106. [CrossRef] [PubMed]

(C) 2020 by the authors. Licensee MDPI, Basel, Switzerland. This article is an open access article distributed under the terms and conditions of the Creative Commons Attribution (CC BY) license (http://creativecommons.org/licenses/by/4.0/). 